\title{
The thermal properties and the flammability of pigmented elastomeric materials
}

\author{
Part I. Phthalocyanine pigments
}

\author{
Agnieszka Pająk • Przemysław Rybiński • \\ Grażyna Janowska $\cdot$ Agnieszka Kucharska-Jastrząbek
}

Received: 10 September 2013/ Accepted: 28 February 2014/Published online: 22 March 2014

(C) The Author(s) 2014. This article is published with open access at Springerlink.com

\begin{abstract}
This paper presents thermal properties of organic pigments such as zinc phthalocyanine and chloroaluminum phthalocyanine that were synthesized according to the literature data. These pigments were characterized by means of elementary analysis and measurements of particle size. They were then incorporated into butadiene-styrene rubber and butadiene-acrylonitrile rubber. The elastomeric mixtures were cross-linked by two methods: using organic peroxide or sulfur. The effect of phthalocyanines on the thermal properties, flammability, and fire hazard of the pigmented polymeric materials obtained as well as on their mechanical properties and cross-linking degree was studied. It has been shown that the phthalocyanine pigments not only impart appropriate esthetic values to the final goods but also increase their thermal stability and considerably reduce the flammability and fire hazard of elastomers and even make possible materials that are self-extinguishing under air atmosphere. These pigments also have a beneficial influence on the degree of cross-linking of the elastomers investigated and their mechanical properties.
\end{abstract}

Keywords Phthalocyanine pigments - Butadiene-styrene rubber (SBR) · Butadiene-acrylonitrile rubber (NBR) · Fire hazard $\cdot$ Thermal analysis

\footnotetext{
A. Pająk - G. Janowska - A. Kucharska-Jastrząbek Institute of Polymer \& Dye Technology, Lodz University of Technology, Łódź, Poland

e-mail: pajak.agnieszka@wp.pl

P. Rybiński ( $\square)$

Management of Environment Protection and Modeling,

The Jan Kochanowski University, Kielce, Poland

e-mail: przemyslaw.rybinski@ujk.edu.pl
}

\section{Introduction}

Phthalocyanines play a very important role among organic pigments as they often possess a high chemical and thermal stability, resistance to the action of light and heat, ease of synthesis, lack of toxicity, and lack of migration to the polymer surface [1-6]. Phthalocyanines and their numerous derivatives constitute the most interesting group of structural analogs of porphyrins. A molecule of phthalocyanine occurs in the form of a characteristic macro-cycle consisting of four indole rings combined with azo bridges that form a system of conjugated double bonds, containing 18 delocalized electrons as illustrated in Fig. 1 and fulfilling Huckle's rule of aromaticity $[1,2,6]$. The indole rings form a closed aromatic plane, whose center contains metal atoms constituting a nucleus of the compound.

Phthalocyanine is a dark-violet crystalline solid insoluble in water. Phthalocyanines have significant absorption in the UV and the red portion of visible spectrum. Hence they are regarded as interesting compounds for various uses from the boundary between chemistry and optics, photochemistry, electronics, biochemistry, and biophysics. Thanks to their spectroscopic, luminescent, and magnetic properties, as well as photo-conductance and photo-emission capabilities, these pigments have found a wide application in industry, which results from the intensive color of the complexes formed with metals. Initially, phthalocyanine derivatives, mostly those of zinc and copper, were used for filling ball-point pen cartridges. Later on, they were used as color pigments in typography and the textile, rubber, plastic, and paint industries as they appeared to be suitable for the preparation of all modifications of blue and green colors [1-6].

This paper presents new findings, not described in the subject literature, concerning the effect of zinc and 
Fig. 1 The structure of applied pigments: a zinc phthalocyanine (FZ), b chloroaluminum phthalocyanine (FC)
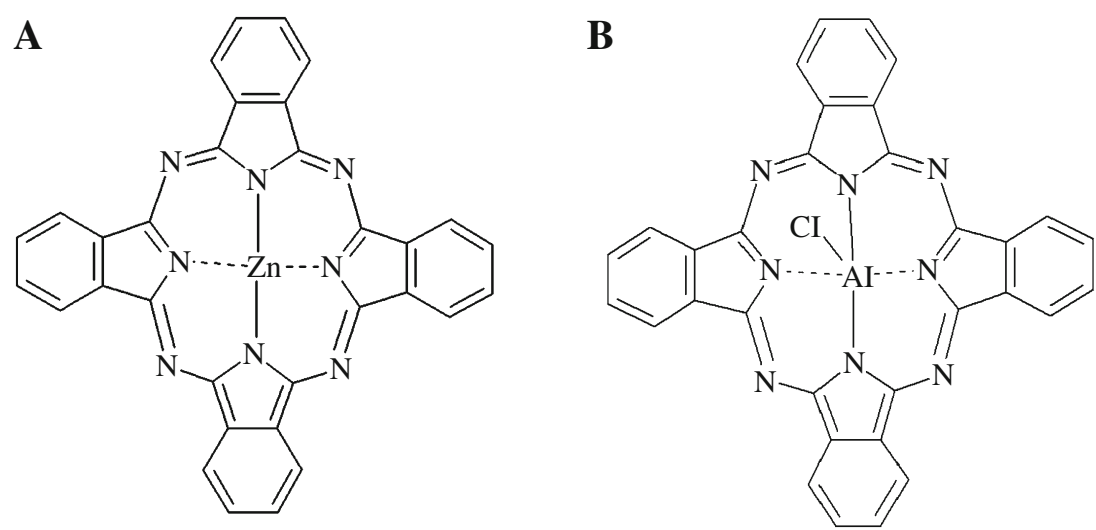

Table 1 Summary of names of obtained composites

\begin{tabular}{|c|c|c|c|c|}
\hline \multirow[t]{3}{*}{ Sample } & \multicolumn{2}{|c|}{$\begin{array}{l}\text { Acrylonitrile-butadiene rubber (NBR) } \\
\left(\text { Perbunan }^{\circledR} 2255 \mathrm{VP}\right) \text { Lanxess Inc. }\end{array}$} & \multicolumn{2}{|c|}{$\begin{array}{l}\text { Styrene-butadiene rubber (SBR) (Ker1500) } \\
\text { Synthos S.A. }\end{array}$} \\
\hline & \multicolumn{4}{|l|}{ Cross-linking agent } \\
\hline & Dicumyl peroxide -Schuchardt & $\begin{array}{l}\text { Sulfur Siarkopol } \\
\text { Tarnobrzeg Sp. z o.o. }\end{array}$ & $\begin{array}{l}\text { Dicumyl peroxide } \\
\text { Merck-Schuchardt }\end{array}$ & $\begin{array}{l}\text { Sulfur Siarkopol } \\
\text { Tarnobrzeg Sp. z o.o. }\end{array}$ \\
\hline- & $\mathrm{NN}$ & NS & SN & SS \\
\hline Zinc Phthalocyanine & NNFZ & NSFZ & SNFZ & SSFZ \\
\hline Chloroaluminum Phthalocyanine & NNFC & NSFC & SNFC & SSFC \\
\hline
\end{tabular}

chloroaluminum phthalocyanines on the thermal properties and flammability of diene elastomers such as butadiene-acrylonitrile rubber (NBR) and butadiene-styrene rubber (SBR).

\section{Experimental}

\section{Materials}

Pigments: zinc phthalocyanine (FZ) and chloraluminum phthalocyanine (FC) were synthesized at the Institute of Polymer and Dye Technology of the Technical University of Lodz, according to the method included in the scientific literature $[3,7]$. They were subjected to acid treatment to wash impurities which they have formed during the synthesis.

The subject of research was elastomeric composites of NBR and SBR. Both elastomers were cross-linked with either dicumyl peroxide or sulfur, accompanied by zinc oxide and stearic acid. As a coloring compound, the zinc phthalocyanine and the chloroaluminum phthalocyanine were applied (Fig. 1; Table 1). These pigments impart a blue color to the elastomeric composites. The shade of blue depends on the particular elastomer and the cross-linking agent used.

\section{Methods}

Elemental analysis of the obtained phthalocyanines was performed at the Polish Academy of Science in Łódź.

Measurement of particle size was determined by means of Analysett 22 NanoTec plus apparatus from Fritsch.

Elastomeric mixtures were prepared at room temperature with the use of a laboratory roll stand with roller dimensions: $D=200 \mathrm{~mm}, L=450 \mathrm{~mm}$. The rotational speed of the front roller was $20 \mathrm{rpm}$ and the posterior roller $22 \mathrm{rpm}$, i.e., the friction ratio is 1.1 .

The mixtures were vulcanized in steel molds placed between electrically heated press shelves. The optimal vulcanization time $\left(\tau_{0,9}\right)$ at a temperature of $160{ }^{\circ} \mathrm{C}$ was determined by means of a WG-2 vulcameter according to PN-ISO 3417:1994, where $\tau_{0,9}$ is the time to reach $90 \%$ of the ultimate storage modulus.

Equilibrium swelling method was used to determine the degree of cross-linking $\left(\alpha_{c}\right)$ of the vulcanizates. Samples were swollen in the toluene at the temperature $T=25{ }^{\circ} \mathrm{C}$ for $48 \mathrm{~h}$ and then removed from the solvent, and the surface toluene was quickly blotted off. The samples were immediately weighed and then dried in a vacuum oven for $36 \mathrm{~h}$ at $80{ }^{\circ} \mathrm{C}$ to remove all the solvent and reweighed. 
The value of equilibrium swelling calculated by the following equation:

$Q_{\mathrm{w}}=\frac{m_{\mathrm{sp}}-m_{\mathrm{s}}}{m_{\mathrm{s}}^{*}}$,

where $Q_{\mathrm{w}}$ equilibrium swelling, $m_{\mathrm{sp}}$ mass of swelling sample (mg), $m_{\mathrm{s}}$ mass of dried sample after swelling (mg), $m_{\mathrm{s}}^{*}$ mass of dried sample after swelling, corrected with the contribution of mineral substances (mg)

$m_{\mathrm{s}}^{*}=m_{\mathrm{s}}-m_{\mathrm{o}}\left(m_{\mathrm{n}} / m_{\mathrm{c}}\right)$,

where $m_{\mathrm{o}}$ initial mass of sample $(\mathrm{mg}), m_{\mathrm{n}}$ mass of mineral substances contained in the rubber mixture $(\mathrm{mg}), m_{\mathrm{c}}$ mass of all rubber mixture components (mg).

The degree of cross-linking $\alpha_{c}$ was calculated by the following equation:

$\alpha_{\mathrm{c}}=\frac{1}{Q_{\mathrm{w}}}$.

The result of equilibrium swelling was an arithmetical average of four determinations.

Thermal analysis of vulcanizates and of pigments was carried out in air by means of the Derivatograph MOM, Hungary, using approximately $90 \mathrm{mg}$ samples at a heating rate of $7.9{ }^{\circ} \mathrm{C} \min ^{-1}$ within the temperature range from 20 to $800{ }^{\circ} \mathrm{C}$. Sensitivity of curves: DTA $=1 / 5$, DTG $=1 / 30$, $\mathrm{TG}=100$. DTA and DTG sensitivity $\left(\mathrm{n}^{-1}\right)$ means that the distance between two points on sensitized paper, corresponding to zero and the maximum deflection of the galvanometer mirror, was reduced n-times. Sensitivity TG 100 means that the distance between two points on sensitized paper, mapping zero, and the maximum deflection of the mirror corresponds to a change of mass amounting to $100 \mathrm{mg}$.

Vulcanizates were also studied in an inert atmosphere using a Netzsch DSC-204 differential scanning calorimetry with approximately $5 \mathrm{mg}$ samples at a cooling and heating rate of $10{ }^{\circ} \mathrm{C} \mathrm{min}^{-1}$ from 20 to -150 and -150 to $500{ }^{\circ} \mathrm{C}$, respectively.

The combustibility of the vulcanizates was determined by the oxygen index (OI) method, using an apparatus of our own design [8], according to the standard PN-ISO 4589-2:1998. The combustibility was also tested in air, using the same apparatus.

The vulcanizates under investigation were also examined by means of the FAA micro-calorimeter from Fire Testing Technology Limited. The temperature of the pyrolyser was $750{ }^{\circ} \mathrm{C}$, while that of combustor $900{ }^{\circ} \mathrm{C}$. During measurement, the following parameters were recorded: ignition temperature $\left(T_{\mathrm{z}}\right)$, maximum heat emission rate $\left(\mathrm{HRR}_{\max }\right)$, total heat emitted (HR), heat capacity, and percentage oxygen consumption. The sample was heated using a linear temperature program, and the volatile thermal degradation products were swept from the pyrolysis chamber by an inert gas and combined with excess oxygen in a tubular furnace at the temperature of $900{ }^{\circ} \mathrm{C}$ to force complete combustion (oxidation) of the fuel. Combustion products $\mathrm{CO}_{2}, \mathrm{H}_{2} \mathrm{O}$, and acid gases were scrubbed from the gas stream, and the transient heat release rate was calculated from the measured flow rate and oxygen concentration after correcting for flow dispersion. The maximum (peak) value of the PCFC heat release rate normalized for the initial sample mass, and heating rate was a material flammability parameter with units of heat release capacity $\left(\mathrm{J} \mathrm{g}^{-1} \mathrm{~K}^{-1}\right)$ which depends only on chemical composition of the sample and is proportional to the burning rate of the material in a fire.

\section{Results and discussion}

The thermal analysis results for zinc phthalocyanine and chloroaluminum phthalocyanine are marked with symbols FZ and FC, respectively, and are listed in Table 2 and shown in Fig. 2. From the thermal curves obtained under air, it follows that these pigments are thermally stable as indicated by the high values of their thermal stability parameters $T_{5}$ and $T_{50}$ (Fig. 2; Table 2). It was then of interest to use them for coloring elastomeric materials characterized by a low thermal stability and fire resistance.

In the thermal curves of FZ and FC, one can observe two characteristic stages of their thermal decomposition (Fig. 2). The beginning of a small mass loss of both phthalocyanines occurs at $T=40{ }^{\circ} \mathrm{C}$ and is connected with a slow evaporation of sorbed water (Fig. 2; Table 2).

The DTA curves of the pigments investigated show endothermic peaks at 340 and $410{ }^{\circ} \mathrm{C}$ connected with the first slow stage of their decomposition, resulting in an initial mass loss of $15 \%$ for FZ and $19 \%$ for FC, respectively (Fig. 2). Intense decomposition of both phthalocyanine pigments begins above $400{ }^{\circ} \mathrm{C}$, as shown by large exothermic peaks recorded in the DTA curves indicating two maxima (Fig. 2). The residue after heating both pigments to $800{ }^{\circ} \mathrm{C}$ is of the same magnitude and amounts to $14 \%$ of the initial sample mass (Table 2).

Thermal analysis carried out under nitrogen showed different characteristics of the thermal processes of both phthalocyanines (Fig. 3).

The DSC of FZ shows two small endothermic transitions at $88{ }^{\circ} \mathrm{C}$ and $351{ }^{\circ} \mathrm{C}$ (Fig. 3a). The first one is connected with a dehydration process, the second with the slow thermal decomposition of FZ, which is also revealed in the TG curve (Fig. 3b) showing a slow, gradual mass loss. Meanwhile, the DSC curve of FC shows a strong endothermic process at $181{ }^{\circ} \mathrm{C}$ (Fig. 3a), which probably indicates the loss of chemically bound water or chlorine 
Table 2 Thermal properties of pigments in air [9]

\begin{tabular}{lllllllll}
\hline Sample & Content of water $/ \%$ & $T_{5} /{ }^{\circ} \mathrm{C}$ & $T_{50} /{ }^{\circ} \mathrm{C}$ & Decomposition stages & $\mathrm{d} m / \mathrm{d} t / \% \times \min ^{-1}$ & $P_{160} / \%$ & $P_{500} / \%$ & $P_{800} / \%$ \\
\hline FZ & 10 & 265 & 470 & I & 4 & 95 & 32 \\
& & & & II & 26 & 14 \\
FC & 14 & 150 & 530 & I & II & 18 & 94 & 68
\end{tabular}

$T_{5} / T_{50}$ temperature of $5 / 50 \%$ mass loss, $\mathrm{d} m / \mathrm{d} t$ maximum rate of thermal decomposition, $P_{160}$ residue of pigment in vulcanization temperature, $P_{500}$ residue of pigment after heating up to $500{ }^{\circ} \mathrm{C}, P_{800}$ residue of pigment after heating up to $800{ }^{\circ} \mathrm{C}$

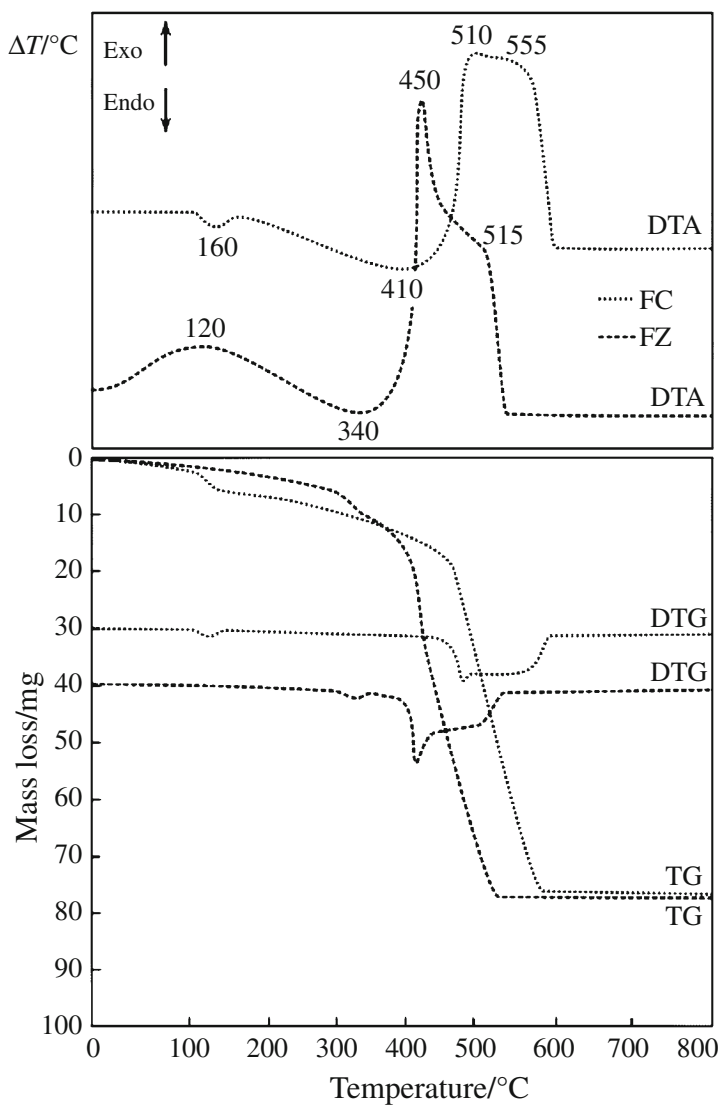

Fig. 2 DTA, TG, and DTG curves of coloring compounds: zinc phthalocyanine (FZ) and chloraluminum phthalocyanine (FC) recorded in air atmosphere

atom from the FC molecule. This process is also shown in TG curves clearly revealing a two-stage process of FC decomposition (Fig. 3b). The end of the first stage occurs at $216{ }^{\circ} \mathrm{C}$. The mass loss after this process amounts to $6 \%$, which is followed by stages of slow FC decomposition.

The comparative analysis of the mass losses of both pigments under nitrogen (Fig. 3b) and under air (Fig. 2, Table 2) leads to a conclusion that after the thermal decomposition of phthalocyanines at $500{ }^{\circ} \mathrm{C}$ in an inert atmosphere, the residue for both pigments is similar: $82 \%$ for $\mathrm{FZ}$ and $86 \%$ for $\mathrm{FC}$, while under air, the corresponding amounts are different: 32 and $68 \%$, respectively.
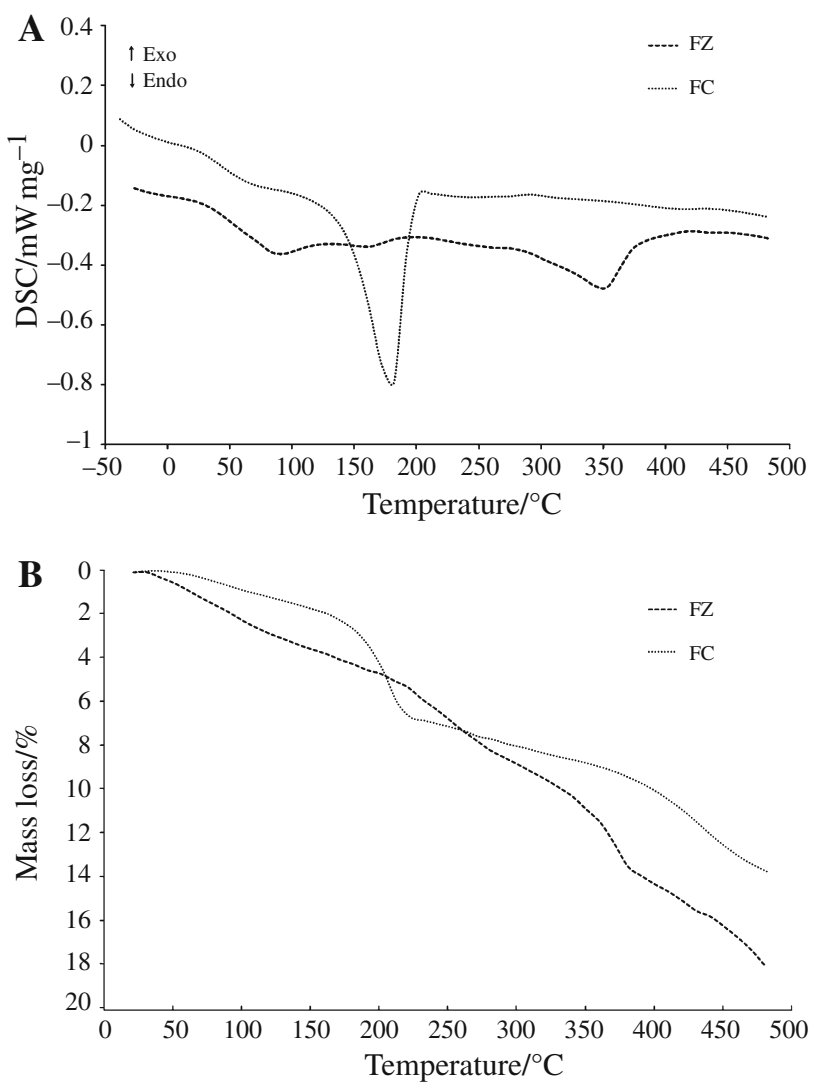

Fig. 3 a DSC and b TG curves of coloring compounds: zinc phthalocyanine (FZ) and chloraluminum phthalocyanine (FC) recorded in nitrogen atmosphere

Based on the elementary analysis of the phthalocyanines synthesized (Table 3), the composition of the elements $\mathrm{C}$, $\mathrm{N}$, and $\mathrm{Cl}$ was found to be similar to that calculated on the basis of their molar masses in the chemical structures of FZ and $\mathrm{FC}$ pigments $\left(\mathrm{C}_{\text {calc. }}, \mathrm{N}_{\text {calc. }}, \mathrm{Cl}_{\text {calc. }}\right)$. Small differences between determined and calculated values are probably due to the presence of elements such as chlorine derived from $\mathrm{HCl}$ solution, in which the pigment was processed to wash out unreacted material and side-products of the phthalocyanine synthesis. This is confirmed by a small increase in the content of chlorine determined during the analysis of FC. Nevertheless, the quantity of impurities in the pigment 
Table 3 The results of the elemental analysis

\begin{tabular}{lllllll}
\hline Sample & $\mathrm{C}_{\text {calc. }} / \%$ & $\mathrm{C} / \%$ & $\mathrm{~N}_{\text {calc. }} / \%$ & $\mathrm{~N} / \%$ & $\mathrm{Cl}_{\text {calc. }} / \%$ & $\mathrm{Cl} / \%$ \\
\hline $\mathrm{FZ}$ & 66 & 63 & 19 & 18 & - & - \\
$\mathrm{FC}$ & 67 & 61 & 19 & 17 & 6 & 8 \\
\hline
\end{tabular}

$\mathrm{C}_{\text {calc }}, \mathrm{N}_{\text {calc }}, \mathrm{Cl}_{\text {calc }}$ the percentage of the element (carbon, nitrogen and chlorine, respectively), calculated based on the molecular mass of the elements. C, N, Cl the participation of elements in a phthalocyanine molecule determined by elemental analysis

Table 4 The particle size of the pigments and their mixtures with $\mathrm{ZnO}(1: 1)$

\begin{tabular}{lc}
\hline Sample & $\begin{array}{l}\text { Arithmetic mean } \\
\text { diameter/ } \mu \mathrm{m}\end{array}$ \\
\hline $\mathrm{FZ}$ & 4.1 \\
$\mathrm{FZ}+\mathrm{ZnO}$ & 4.2 \\
$\mathrm{FC}$ & 10.1 \\
$\mathrm{FC}+\mathrm{ZnO}$ & 4.7 \\
\hline
\end{tabular}

obtained is insignificant as supported by the small mass losses in the initial processes recorded in the thermal curves of these pigments (Figs. 2, 3).

The particle size of the pigments was determined before their incorporation into the plasticized rubber. The particle size of these pigments mixed with zinc oxide (1:1), which was added to the elastomers, was also measured. These measurements showed that the molecules of both pigments underwent agglomeration in different ways, which influenced the size of pigment particles (Table 4).

Pigment FC, probably due to the presence of chlorine atom protruding from the molecular plane (Fig. 1b), is characterized by larger particle sizes than those of $\mathrm{FZ}$ (Fig. 1a; Table 4). Mixing FC pigment with amphoteric zinc oxide by grinding in a mortar probably causes a reduction in intermolecular interactions that may occur between chlorine atoms of adjacent phthalocyanine molecules in its agglomerates, which manifests itself as a decrease in the particle size of the mixture of $\mathrm{FC}$ and $\mathrm{ZnO}$ investigated. It is also possible that ligands are formed, from which chemically bound water is removed at $160{ }^{\circ} \mathrm{C}$ (Fig. 2, a small endothermic peak in the DTA curve) and at $180{ }^{\circ} \mathrm{C}$ (Fig. 3a, endothermic peak in the DSC curve). On the other hand, the peaks shown in DTA and DSC curves in this temperature range may result from the detachment of chlorine from FC molecule or from both these phenomena occurring at the same time.

Meanwhile, FZ and its mixture with $\mathrm{ZnO}$ are characterized by almost the same size of particles. The absence of ligand bonds between FZ pigment and water is supported by lower water content than that in the case of FC determined by thermal analysis under air (Table 2).
Table 5 Influence of phthalocyanine pigments on the cross-linking degree and mechanical properties of NBR and SBR vulcanizates

\begin{tabular}{lllll}
\hline Sample & $\tau_{0,9} / \mathrm{min}$ & $\alpha_{\mathrm{c}}$ & $\mathrm{TS}_{\mathrm{b}} / \mathrm{MPa}$ & $E_{\mathrm{b}} / \%$ \\
\hline NN & 25 & 0.136 & 2.80 & 580 \\
NNFZ & 35 & 0.157 & 3.37 & 560 \\
NNFC & 40 & 0.168 & 3.72 & 626 \\
NS & 15 & 0.301 & 2.69 & 415 \\
NSFZ & 10 & 0.395 & 3.53 & 158 \\
NSFC & 22 & 0.306 & 2.96 & 290 \\
SN & 60 & 0.132 & 2.80 & 580 \\
SNFZ & 50 & 0.137 & 2.96 & 614 \\
SNFC & 60 & 0.151 & 2.75 & 561 \\
SS & 20 & 0.223 & 2.37 & 364 \\
SSFZ & 15 & 0.302 & 3.24 & 174 \\
SSFC & 23 & 0.213 & 3.23 & 463 \\
\hline
\end{tabular}

$\tau_{90}$ the optimal vulcanization time, $\alpha_{c}$ degree of cross-linking, $T S_{b}$ vulcanizate tensile strength at break, $E_{b}$ elongation at break

The presence of phthalocyanine pigments in the elastomeric mixtures exerts a significant influence on their cross-linking processes, which may be accompanied by processes of thermal degradation of macromolecules studied elastomers. The comparative analysis of data presented in Table 5 leads to a conclusion that independent of the chemical structure of the polymers under investigation or the type of cross-linker, the cross-linking during vulcanization proceeds faster under the influence of FZ. This suggests that the observed acceleration in the rate of crosslink formation is due to the presence of zinc. It should be also emphasized that in the case of both elastomers, their cross-linking degree by means of sulfur in the presence of $\mathrm{FZ}\left(\alpha_{\mathrm{c}}\right)$ is considerably higher than that in the presence of FC (Table 5). Moreover, phthalocyanines increase the degree of cross-linking, $\alpha_{c}$, of the rubber mixture regardless of the type of elastomer and the cross-linking procedure (Table 5).

The results presented in Table 5 show that the mechanical properties of cross-linked NBR are clearly better than those of cross-linked SBR. This conclusion is based, firstly, on the different cohesion energy densities of SBR and NBR, 335.6 and $432.1 \mathrm{MJ} \mathrm{m}^{-3}$, respectively. Our investigations have shown a positive effect of phthalocyanines on the mechanical properties, based on the tensile strength of both rubbers cross-linked by the sulfur crosslinking system.

From results obtained by the DSC method, it follows that the pigments used do not change the character of transitions of the elastomers investigated (Fig. 4). However, the presence of phthalocyanines increases the glass transition temperature, $T_{\mathrm{g}}$, of the rubbers, during both cooling and heating (Table 6). The increase in $T_{\mathrm{g}}$ of 

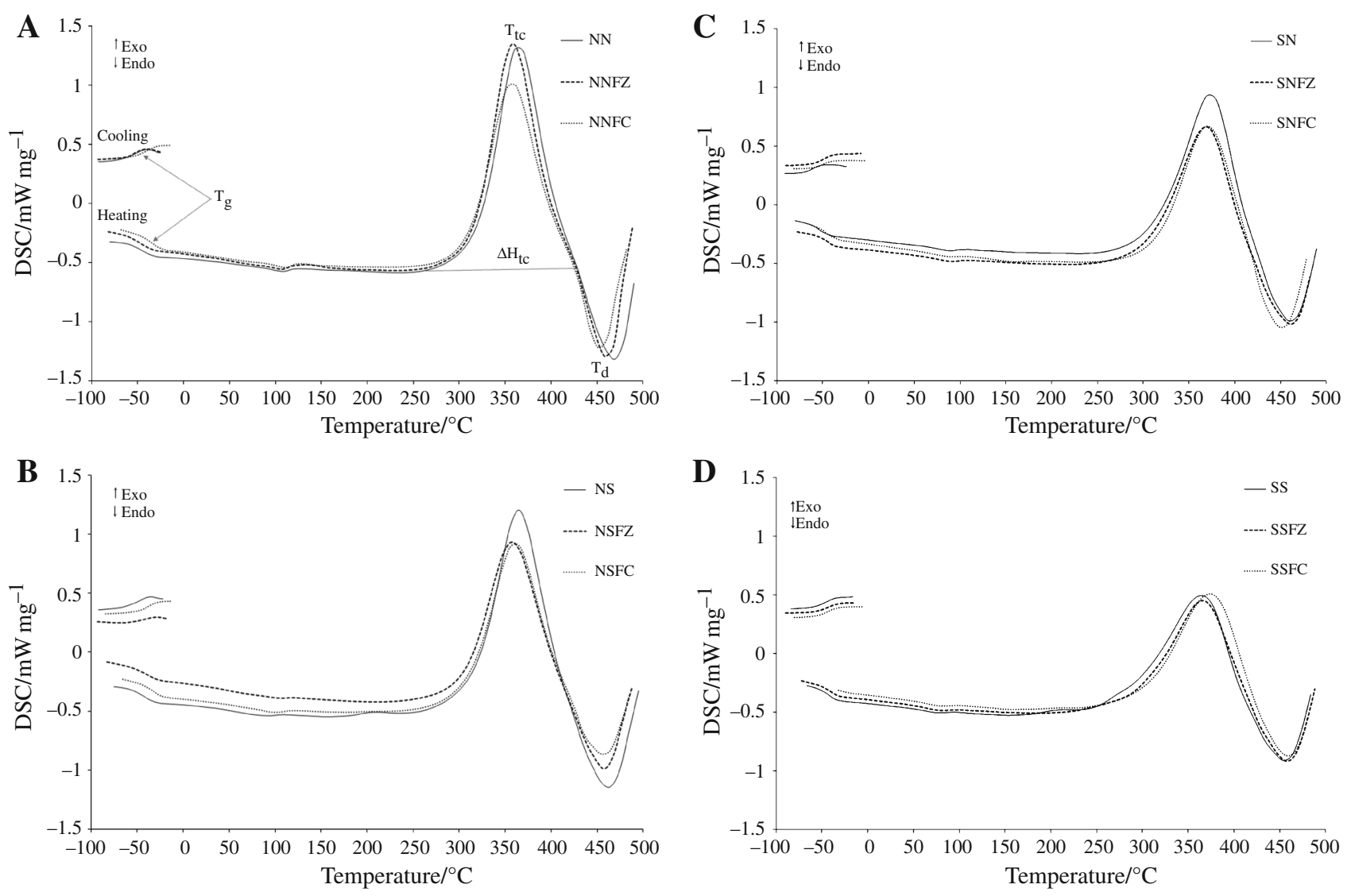

Fig. 4 DSC curves of colored vulcanizates: a NBR cross-linked with DCP, b NBR cross-linked with sulfur, c SBR cross-linked with DCP, d SBR cross-linked with sulfur

Table 6 Results of thermal analysis of NBR and SBR composites carried out in nitrogen

\begin{tabular}{|c|c|c|c|c|c|c|c|}
\hline \multirow[t]{2}{*}{ Sample } & \multicolumn{2}{|c|}{ Cooling } & \multicolumn{5}{|c|}{ Heating } \\
\hline & $T_{\mathrm{g}} /{ }^{\circ} \mathrm{C}$ & $\Delta T_{\mathrm{g}} /{ }^{\circ} \mathrm{C}$ & $T_{\mathrm{g}} /{ }^{\circ} \mathrm{C}$ & $\Delta T_{\mathrm{g}} /{ }^{\circ} \mathrm{C}$ & $T_{\mathrm{tc}} /{ }^{\circ} \mathrm{C}$ & $\Delta H_{\mathrm{tc}} / \mathrm{J} \mathrm{g}^{-1}$ & $T_{\mathrm{d}} /{ }^{\circ} \mathrm{C}$ \\
\hline $\mathrm{NN}$ & -50 & -40 to -80 & -45 & -66 to -26 & 364 & 630 & 469 \\
\hline NNFZ & -53 & -49 to -57 & -41 & -57 to -35 & 358 & 646 & 462 \\
\hline NNFC & -40 & -29 to -51 & -33 & -44 to -26 & 357 & 591 & 455 \\
\hline NS & -46 & -36 to -86 & -42 & -62 to -22 & 365 & 650 & 462 \\
\hline NSFZ & -39 & -30 to -47 & -36 & -43 to -29 & 358 & 505 & 459 \\
\hline NSFC & -37 & -31 to -43 & -32 & -39 to -25 & 360 & 538 & 458 \\
\hline SN & -60 & -50 to -78 & -53 & -74 to -34 & 374 & 594 & 462 \\
\hline SNFZ & -49 & -43 to -55 & -45 & -50 to -40 & 369 & 514 & 462 \\
\hline SNFC & -50 & -45 to -55 & -44 & -49 to -39 & 370 & 501 & 452 \\
\hline SS & -45 & -31 to -61 & -41 & -59 to -19 & 364 & 571 & 456 \\
\hline SSFZ & -44 & -34 to -53 & -40 & -46 to -36 & 366 & 527 & 458 \\
\hline SSFC & -43 & -36 to -50 & -36 & -40 to -34 & 373 & 559 & 459 \\
\hline
\end{tabular}

$T_{\mathrm{g}}$ glass transition temperature, $\Delta T_{\mathrm{g}}$ temperature range of glass transition, $T_{\mathrm{tc}}$ temperature of the maximal thermal cross-linking rate, $\Delta T_{\mathrm{tc}}$ temperature range of the thermal cross-linking process, $\Delta H_{\mathrm{tc}}$ change of the thermal cross-linking enthalpy, $T_{\mathrm{d}}$ temperature of the maximal destruction rate

pigmented elastomers results from the fact that the degree of their cross-linking is higher $\left(\alpha_{c}\right.$, Table 5), which decreases the segmental mobility of the macromolecular chains.
From the DSC analysis, it follows that phthalocyanines clearly inhibit the thermal cross-linking processes of SBR and NBR under nitrogen, regardless of the cross-linker used, as shown by lower heat of reaction for this process, 
A

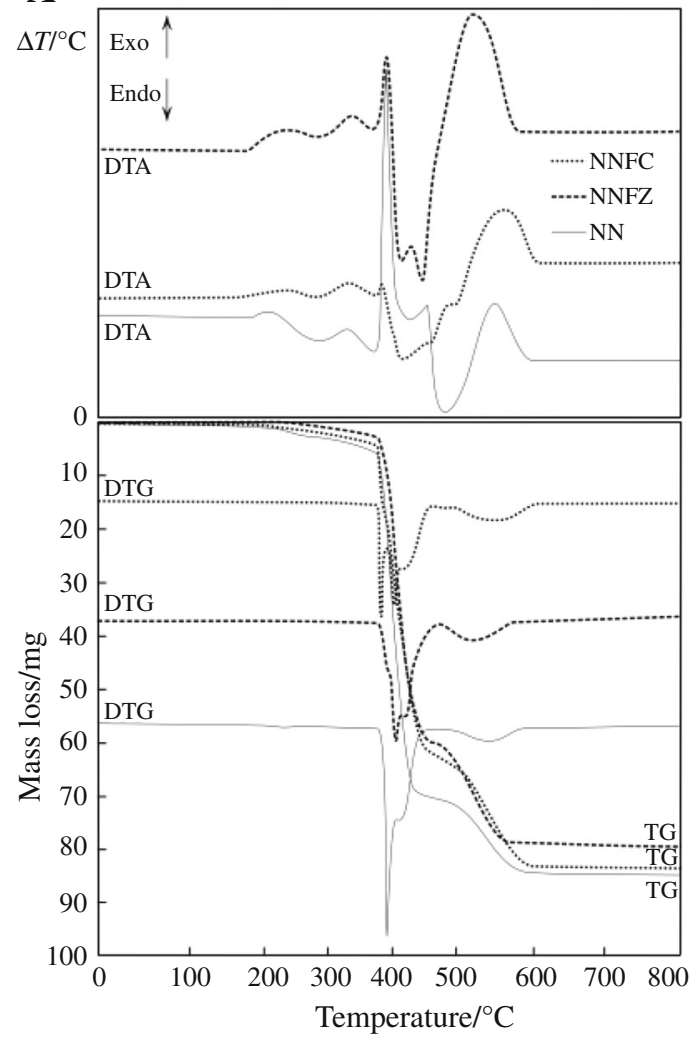

C

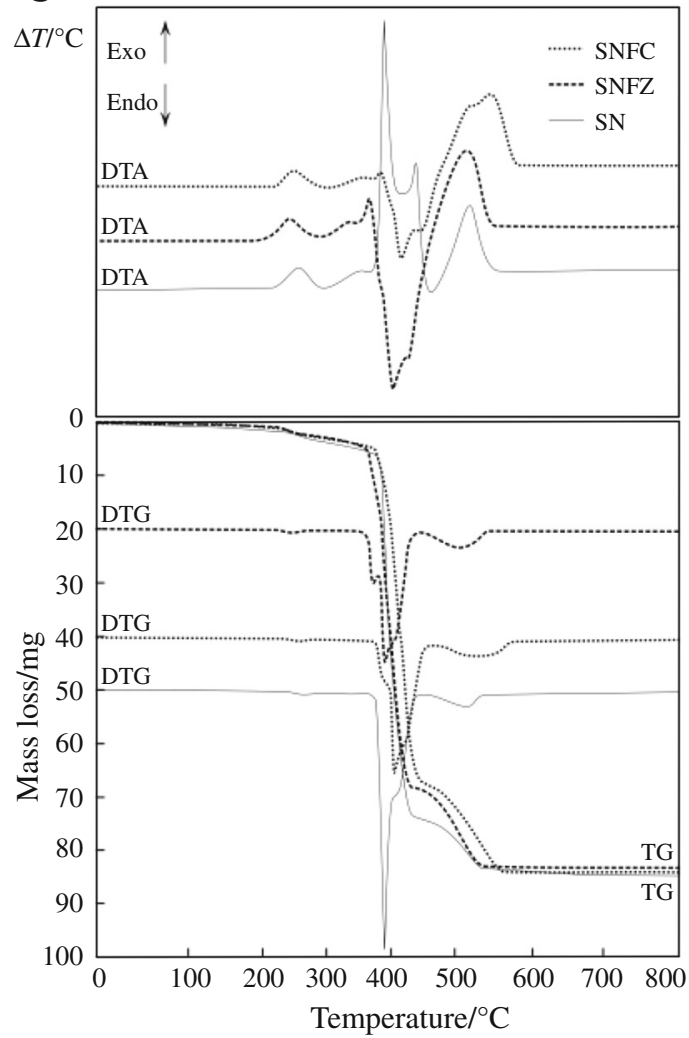

B

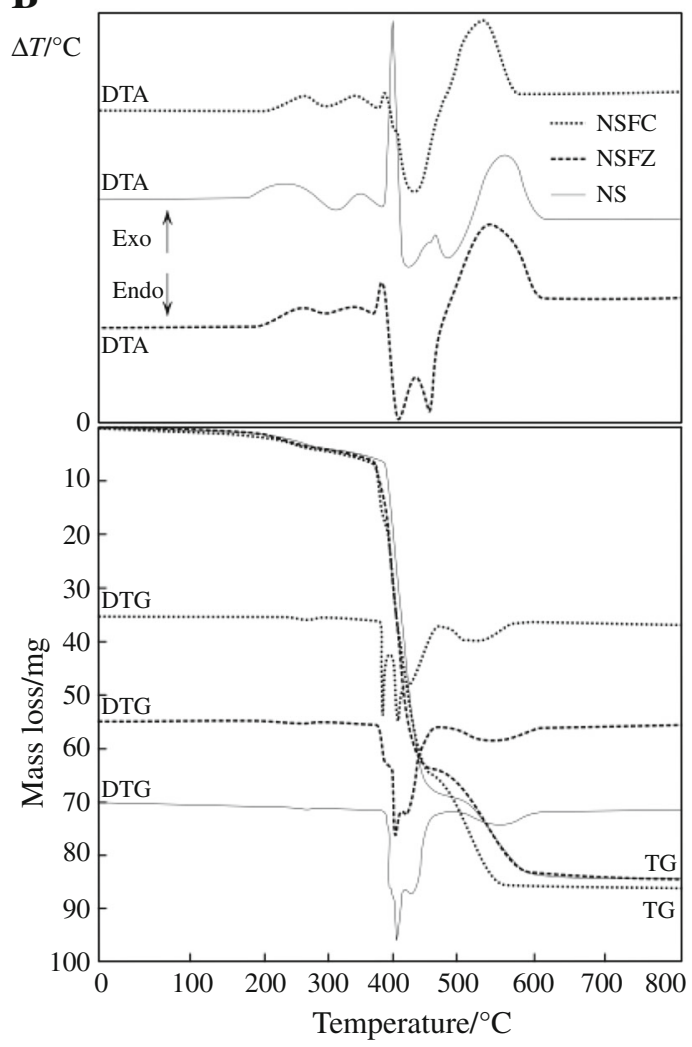

D

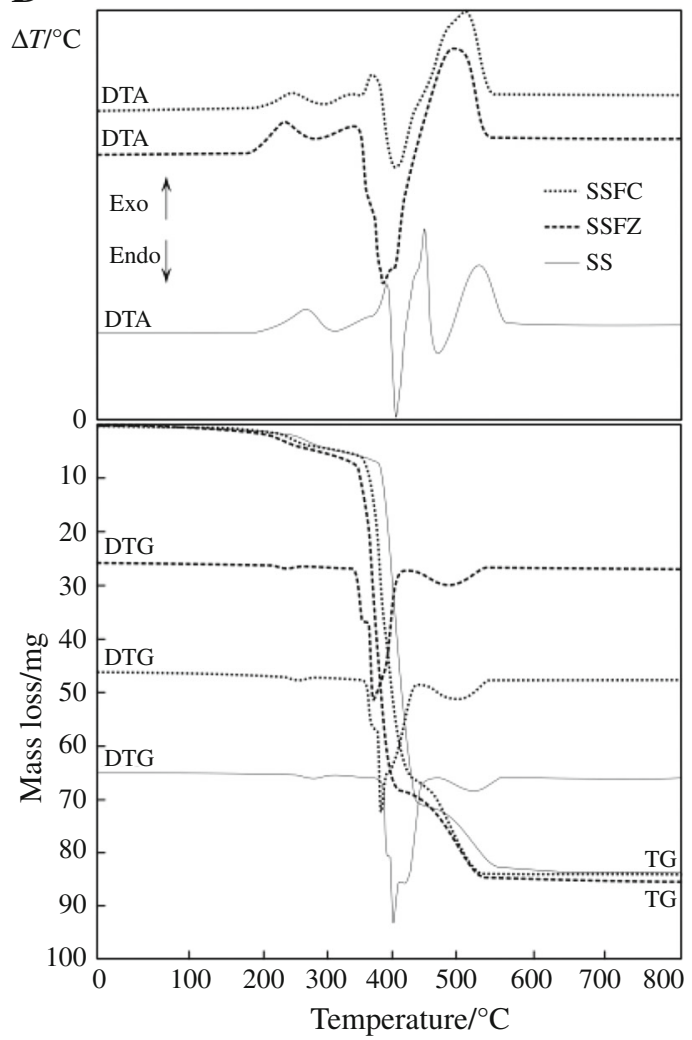

Fig. 5 Results of thermal analysis of colored vulcanizates: a NBR cross-linked with DCP, b NBR cross-linked with sulfur, c SBR cross-linked with DCP, d SBR cross-linked with sulfur 
Table 7 Results of thermal analysis of NBR and SBR composites carried out in air atmosphere

\begin{tabular}{llllllc}
\hline Sample & $T_{5} /{ }^{\circ} \mathrm{C}$ & $T_{50} /{ }^{\circ} \mathrm{C}$ & $\begin{array}{l}\mathrm{d} m / \mathrm{d} t / \\
\% \times \mathrm{min}^{-1}\end{array}$ & $P_{\mathrm{w}} / \%$ & $T \mathrm{~s} /{ }^{\circ} \mathrm{C}$ & $P_{800} / \%$ \\
\hline NN & 350 & 420 & 70 & 23 & 545 & 7 \\
NNFZ & 385 & 425 & 45 & 34 & 525 & 11 \\
NNFC & 375 & 425 & 43 & 32 & 565 & 7 \\
NS & 315 & 405 & 52 & 23 & 540 & 7 \\
NSFZ & 320 & 415 & 42 & 31 & 545 & 6 \\
NSFC & 300 & 425 & 38 & 29 & 530 & 5 \\
SN & 350 & 419 & 80 & 18 & 475 & 5 \\
SNFZ & 350 & 410 & 49 & 24 & 520 & 7 \\
SNFC & 340 & 405 & 51 & 26 & 540 & 7 \\
SS & 300 & 400 & 70 & 21 & 490 & 9 \\
SSFZ & 280 & 400 & 50 & 25 & 515 & 4 \\
SSFC & 300 & 405 & 51 & 26 & 515 & 7 \\
\hline
\end{tabular}

$T_{5} / T_{50}$ temperature of $5 \% / 50 \%$ mass loss, $\mathrm{d} m / \mathrm{d} t$ maximum rate of thermal decomposition, $P_{\mathrm{w}}$ residue after thermal decomposition of vulcanizate, $T s$ maximum combustion temperature rate of residue after thermal decomposition, $P_{800}$ residue after heating up to $800{ }^{\circ} \mathrm{C}$

$\Delta H_{\text {tc }}$ (Fig. 4; Table 6). Except for the sulfur vulcanizates of SBR, FZ and FC slightly decrease the temperature of the maximum thermal cross-linking rate, $T_{\mathrm{tc}}$. The presence of the pigments in these vulcanizates also causes a shift in the destruction temperature, $T_{\mathrm{d}}$, toward lower values (Table 6).

Based on the results of thermal analysis performed under air (Fig. 5; Table 7), it has been found that phthalocyanine pigments do not affect on the exothermic processes recorded in DTA curves at 240-255 and $335-360{ }^{\circ} \mathrm{C}$. The effect of the pigments is seen in the temperature range $365-465{ }^{\circ} \mathrm{C}$, where the decomposition of the vulcanizates occurs. The residue after thermal decomposition, $P_{\mathrm{w}}$, of the pigmented elastomeric materials is considerably greater than that of the vulcanizates containing no phthalocyanines (Fig. 5; Table 7). The thermal decomposition rate of the vulcanizates, $\mathrm{d} m / \mathrm{d} t$, is also decreased (Fig. 5; Table 7). Thus, the phthalocyanines facilitate the processes of cyclization and charring of the elastomers tested, which is clearly seen in the case of NBR that is characterized by higher cohesion energy than that of SBR. This favors a decrease in the oxygen diffusion rate to the zone of chemical reactions and thereby reduces their rate. Thus, a smaller quantity of volatile and flammable decomposition products is formed, which should reduce the flammability of the colored vulcanizates compared to those containing no phthalocyanine.

Phthalocyanines exert no significant influence on the combustion process of the residue remaining after the thermal decomposition of vulcanizates, which was recorded in the DTA curves at $T>515{ }^{\circ} \mathrm{C}$. Nevertheless, pigments influence the residue after heating sample up to $800{ }^{\circ} \mathrm{C} . P_{800}$ amounts to $4-11 \%$ (Table 7).

The comparative analysis of the test results obtained (Table 7) allows one to conclude that phthalocyanines significantly increase the thermal stability $\left(T_{5}\right)$ of the peroxide vulcanizates regardless of the chemical structure of the elastomer. However, they exert no significant effect on the thermal stability determined by parameter $T_{50}$.

The test results of the thermal properties of the elastomeric materials were used as the basis for interpreting the measurement results of their flammability. The phthalocyanine pigments used significantly improve the thermal stability of the pigmented NBR composites based on parameters such as $T_{5}, \mathrm{~d} m / \mathrm{d} t$, and $P_{\mathrm{w}}$ (Fig. 5; Table 7) and

Table 8 Flammability test results of elastomeric composites containing NBR or SBR rubber

\begin{tabular}{|c|c|c|c|c|c|c|c|}
\hline Sample & $\mathrm{OI} / \%$ & $t_{\mathrm{s}} / \mathrm{s}$ & $T_{\mathrm{z}} /{ }^{0} \mathrm{C}$ & $\begin{array}{l}\mathrm{HRR}_{\max } / \\
\mathrm{W} \mathrm{g}\end{array}$ & $\begin{array}{l}\text { Total HR/ } \\
\mathrm{kJ} \mathrm{g}^{-1}\end{array}$ & $\begin{array}{l}\text { HR Capacity/ } \\
\mathrm{J} \mathrm{g}^{-1} \mathrm{~K}^{-1}\end{array}$ & $\begin{array}{l}\text { Oxygen } \\
\text { consumption/\% }\end{array}$ \\
\hline $\mathrm{NN}$ & 20.5 & 276 & 357 & 472 & 34.0 & 479 & 50.02 \\
\hline NNFZ & 24.1 & 450 & 358 & 490 & 32.1 & 483 & 87.92 \\
\hline NNFC & 23.3 & $118^{\mathrm{a}}(14)$ & 362 & 451 & 30.4 & 445 & 60.44 \\
\hline NS & 21.5 & 289 & 366 & 432 & 32.0 & 432 & 67.09 \\
\hline NSFZ & 22.0 & 332 & 365 & 415 & 30.8 & 407 & 54.04 \\
\hline NSFC & 24.2 & $113^{\mathrm{a}}(12)$ & 357 & 393 & 31.2 & 384 & 31.60 \\
\hline SN & 21.0 & 194 & 350 & 450 & 34.5 & 501 & 40.11 \\
\hline SNFZ & 24.3 & 304 & 365 & 435 & 35.5 & 432 & 44.96 \\
\hline SNFC & 26.0 & 240 & 371 & 379 & 33.9 & 375 & 41.00 \\
\hline SS & 22.0 & 273 & 355 & 399 & 34.3 & 397 & 44.91 \\
\hline SSFZ & 22.9 & 307 & 364 & 373 & 34.8 & 390 & 27.58 \\
\hline SSFC & 24.6 & 346 & 360 & 389 & 34.4 & 381 & 46.36 \\
\hline
\end{tabular}

$O I$ oxygen index, $t_{\mathrm{s}}$ time of burning in air atmosphere, $T_{\mathrm{z}}$ temperature of ignition, $H R R_{\max }$ maximum heat release rate, Total $H R$ total heat release

${ }^{a}$ Self-extinguishing materials - in parentheses are percent $(\%)$ of the burned section of the sample 
also exert a clear influence on the reduction in their flammability.

Regardless of the chemical structure of the elastomer macromolecules, the phthalocyanine pigments used clearly increase the value of oxygen index of the vulcanizates. The pigmented vulcanizates of SBR and NBR, regardless of the cross-linking agent used, are characterized by a significantly longer time of burning in air, $\mathrm{t}_{\mathrm{s}}$ (Table 8).

Moreover, the incorporation of FC into NBR, regardless of its network structure, makes it possible to obtain selfextinguishing materials in air (NNFC, NSFC), which is probably connected with the presence of chlorine atom in the pigment molecular structure (Fig. 1b). This favors the formation of $\mathrm{HCl}$ during thermal decomposition of the pigmented elastomeric materials. Chlorine compounds are often used as flame-retardant substances in polymeric materials [10, 12-16]. However, it is worth noticing that chloroaluminum phthalocyanine is a pigment of complex character, as evidenced by its neutral effect on the environment and living organisms. It is possible to obtain self-extinguishing NBR vulcanizates containing $\mathrm{FC}$ due to their very low thermal decomposition rate under thermo-oxidative conditions $(\mathrm{d} m /$ $\mathrm{d} t$, Table 7), which is due to the partly ionic decomposition of cross-linked NBR induced by the presence of $\mathrm{HCl}$. As a result of the decreased thermal decomposition rate, a lower quantity of volatile and flammable decomposition products passes to the combustion zone, which also results in the reduction in the mass and heat transport to the flame zone $[10,11]$. This phenomenon helps to reduce the flammability of the materials under investigation.

It also seems possible that the self-extinguishing properties of samples containing FC are due to the presence the ligand bonds mentioned earlier, which can be formed by the molecule of FC with water. During combustion, owing to high temperatures, $\mathrm{H}_{2} \mathrm{O}$ released from the $\mathrm{FC}$ structure dilutes the volatile and flammable NBR thermal decomposition products, which results in fire suppression. In the case of SBR, such a phenomenon was not observed, which probably results from the nonpolar structure of this polymer, where its interaction with water molecules is impeded. Nevertheless, under the influence of FC, the time of combustion in air is significantly prolonged, and the oxygen index is clearly increased (SNFC, SSFC, Table 8) compared to samples containing no FC.

With the exception of the sulfur vulcanizates of NBR, the effect of both pigments is to reduce flammability of the polymers under investigation, due to the considerable increase in ignition temperature $\mathrm{T}_{\mathrm{z}}$ (Table 8).

It is also of important to note that the phthalocyanines studied reduce the fire hazard as judged by the heat release rate, $\mathrm{HRR}_{\max }$, which is a propelling force of fire $[11,12,17,18]$. The data show (Table 8) a decreased value in relation to that of rubbers without these colored pigments. This phenomenon is very beneficial from the point of view of reducing fire hazard and should be taken into special consideration in designing the composition of flame-retardant composites. The positive effect of phthalocyanines on the reduction in fire hazard is also confirmed by the total heat release during combustion (Total HR), especially in the case of NBR vulcanizates.

Contrary to expectations, FZ and FC pigments slightly decrease the heat capacity of vulcanizates (Table 8). An increase in heat capacity is usually observed and is associated with a beneficial effect on flammability [19]. On the other hand, it is worth noting that in the case of pigmented elastomeric materials marked with symbols: SSFZ, NSFZ, and NSFC, a significant reduction in oxygen consumption during combustion was observed, which is beneficial in terms of fire hazard reduction. In the remaining cases, the amount of oxygen consumed during the combustion of phthalocyanine-containing composites is similar to that observed in unpigmented composites.

\section{Conclusions}

The results of this investigation show that the incorporation of phthalocyanine pigments into SBR or NBR elastomers enhances specific mechanical properties, imparts an appropriate esthetic quality and leads to an increase in thermal stability and reduction in flammability and fire hazard. The pigments used impart flame-retardant properties to the elastomers investigated. The use of chloroaluminum phthalocyanine imparted self-extinguishing properties to polymeric materials containing NBR.

The use of phthalocyanine pigments to improve the thermal stability and reduce flammability of diene rubbers is also beneficial for their mechanical properties. The pigments used increase the thermal stability of elastomeric materials, determined by $T_{5}, \mathrm{~d} m / \mathrm{d} t$, and $P_{\mathrm{w}}$ parameters. Fire hazard was reduced due to the reduced thermal decomposition rate and the increased residue remaining after this process owing to the extended combustion time under air, increased oxygen index, and decreased heat release rate.

Open Access This article is distributed under the terms of the Creative Commons Attribution License which permits any use, distribution, and reproduction in any medium, provided the original author(s) and the source are credited.

\section{References}

1. Stiepanow BI. Podstawy chemii i technologii barwników organicznych. Warszawa: Wydawnictwo Naukowo Techniczne; 1980.

2. Moser FH, Thomas AL. The phthalocyanines-properties, vol. I. Florida: CRC Press; 1983.

3. Moser FH, Thomas AL. The phthalocyanines-manufacture and applications, vol. II. Florida: CRC Press; 1983. 
4. Smith HM. High performance pigments. Weinheim: Wiley; 2002. p. 263-79.

5. Herbst W, Hunger K. Industrial organic pigments: production, properties, applications. Weinheim: Wiley; 1997.

6. Fiedurek J, Makarska M, Polska K, Radzki S. Trytek M Porfiryny i ftalocyjaniny. Cz. I. Właściwości i niektóre zastosowania. Łódź: Prace przeglądowe; 2005.

7. Heilbron IM, Irving F, Linstead RP. US Patent No. 2,202, 632, 1940.

8. Ślusarski L., Janowska G., Szkodziński A., Niedomagała M., Hawraziński A. Polish Patent No. 12941, 1987.

9. Pająk A, Janowska G, Czajkowski W, Kucharska-Jastrząbek A. Wpływ pigmentów ftalocyjaninowych na właściwości kauczuku butadienowego. Przemysł Chemiczny. 2010;89(12):1689-92.

10. Janowska G, Przygocki W, Włochowicz A. Palność polimerów i materiałów polimerowych. Warszawa: Wydawnictwo Naukowo Techniczne; 2007.

11. Rybiński P, Janowska G, Kucharska-Jastrząbek A, Pająk A, Wójcik I, Wesołek D, Bujnowicz K. Flammability of vulcanizates of diene rubbers. J Therm Anal Calorim. 2012;107(3): 1219-24.

12. Iwko J. Uniepalnianie tworzyw sztucznych. Zachowanie się tworzyw sztucznych w warunkach pożarowych. Część IIpomiary palności oraz metody uniepalniania tworzyw sztucznych. Tworzywa Sztuczne i Chemia. 2009;6:24-9.
13. Zhao Peihua, Zhang Mei, Denghui Wu, Liu Yaqing. Synthesis of a novel triazine flame retardant containing sulfur and its application to cotton fabrics. Korean J Chem Eng. 2013;30(9):1687-90.

14. Ma Y, Wang J, Xu Y, Wang C. Fuxiang C Preparation and characterization of phenolic foams with eco-friendly halogen-free flame retardant. J Therm Anal Calorim. 2013;. doi:10.1007/ s10973-013-3180-6.

15. Ye L, Zhang Y, Wang S, Gao G, Liu J, Zhou Y, Liu H. Synergistic effects and mechanism of $\mathrm{ZnCl}_{2}$ on intumescent flameretardant polypropylene. J Therm Anal Calorim. 2013; d doi:10. 1007/s10973-013-3381-z.

16. Rybiński P, Janowska G, Dobrzyńska R, Kucharska A. Effect of halogenless flame retardants on the thermal properties, flammability, and fire hazard of cross-linked EVM/NBR rubber blends. J Therm Anal Calorim. 2013; doi:10.1007/s10973-013-3333-7.

17. Rybiński P, Janowska G, Jóźwiak M, Pająk A. Thermal properties and flammability of nanocomposites based on diene rubbers and naturally occurring and activated halloysite nanotubes. J Therm Anal Calorim. 2012;107(3):1243-9.

18. Rybiński P, Janowska G, Jóźwiak M, Pająk A. Thermal stability and flammability of butadiene-styrene rubber nanocomposites. J Therm Anal Calorim. 2012;109(2):561-71.

19. Rybiński P, Janowska G. Thermal stability and flammability of nanocomposities made of diene rubbers and modified halloysite nanotubes. J Therm Anal Calorim. 2013;113:31-41. 